\title{
Dietary Patterns and Mortality in a Multinational Cohort of Adults Receiving Hemodialysis
}

\author{
Valeria M. Saglimbene, Germaine Wong, Armando Teixeira-Pinto, Marinella Ruospo, Vanessa Garcia-Larsen, \\ Suetonia C. Palmer, Patrizia Natale, Katrina Campbell, Juan-Jesus Carrero, Peter Stenvinkel, Letizia Gargano, \\ Angelo M. Murgo, David W. Johnson, Marcello Tonelli, Rubén Gelfman, Eduardo Celia, Tevfik Ecder, \\ Amparo G. Bernat, Domingo Del Castillo, Delia Timofte, Marietta Török, Anna Bednarek-Skublewska, \\ Jan Duława, Paul Stroumza, Martin Hansis, Elisabeth Fabricius, Paolo Felaco, Charlotta Wollheim, \\ Jörgen Hegbrant, Jonathan C. Craig, and Giovanni F.M. Strippoli, on behalf of the DIET-HD Investigators and \\ Dieticians
}

\begin{abstract}
Rationale \& Objective: Clinical practice guidelines for dietary intake in hemodialysis focus on individual nutrients. Little is known about associations of dietary patterns with survival. We evaluated the associations of dietary patterns with cardiovascular and all-cause mortality among adults treated by hemodialysis.
\end{abstract}

Study Design: Prospective cohort study.

Setting \& Participants: 8,110 of 9,757 consecutive adults on hemodialysis (January 2014 to June 2017) treated in a multinational private dialysis network and with analyzable dietary data.

Exposures: Data-driven dietary patterns based on the $G A^{2} L E N$ food frequency questionnaire. Participants received a score for each identified pattern, with higher scores indicating closer resemblance of their diet to the identified pattern. Quartiles of standardized pattern scores were used as primary exposures.

Outcomes: Cardiovascular and all-cause mortality.

Analytical Approach: Principal components analysis with varimax rotation to identify common dietary patterns. Adjusted proportional hazards regression analyses with country as a random effect to estimate the associations between dietary pattern scores and mortality. Associations were expressed as adjusted HRs with $95 \% \mathrm{Cls}$, using the lowest quartile score as reference.

Results: During a median follow-up of 2.7 years (18,666 person-years), there were 2,087 deaths (958 cardiovascular). 2 dietary patterns, "fruit and vegetable" and "Western," were identified. For the fruit and vegetable dietary pattern score, adjusted $\mathrm{HRs}$, in ascending quartiles, were $0.94(95 \% \mathrm{Cl}, 0.76-1.15), 0.83(95 \% \mathrm{Cl}$, $0.66-1.06)$, and $0.91(95 \% \mathrm{Cl}, 0.69-1.21)$ for cardiovascular mortality and $0.95(95 \% \quad \mathrm{Cl}$, 0.83-1.09), 0.84 (95\% Cl, 0.71-0.99), and 0.87 $(95 \% \mathrm{Cl}, 0.72-1.05)$ for all-cause mortality. For the Western dietary pattern score, the corresponding estimates were $1.10(95 \% \mathrm{Cl}$, $0.90-1.35), 1.11(95 \% \mathrm{Cl}, 0.87-1.41)$, and 1.09 (95\% Cl, 0.80-1.49) for cardiovascular mortality and $1.01(95 \% \mathrm{Cl}, 0.88-1.16), 1.00(95 \% \mathrm{Cl}$, $0.85-1.18)$, and $1.14(95 \% \mathrm{Cl}, 0.93-1.41)$ for all-cause mortality.

Limitations: Self-reported food frequency questionnaire, data-driven approach.

Conclusions: These findings did not confirm an association between mortality among patients receiving long-term hemodialysis and the extent to which dietary patterns were either high in fruit and vegetables or consistent with a Western diet.
Complete author and article information (including a list of the DIET-HD

Investigators and

Dieticians) provided before references.

Correspondence to

V.M. Saglimbene

(vsag1982@gmail.com)

Am J Kidney Dis. $X X(X X): 1$. 12. Published online Month $X, X X X X$.

doi: 10.1053/

j.ajkd.2019.05.028

(C) 2019 by the National Kidney Foundation, Inc.
$\mathrm{T}$ he risk for premature death among patients with endstage kidney disease is high. People who commence long-term hemodialysis therapy can expect to live for only 3 to 4 years on average, ${ }^{1}$ with cardiovascular disease responsible for $\sim 40 \%$ of these deaths. ${ }^{2}$ In contrast to findings from the general population, interventions directed at lowering lipid levels, controlling blood pressure and glucose levels, and preventing thrombosis have shown minimal or no survival benefits in this at-risk population. ${ }^{3-6}$ Identification of strategies that prevent cardiovascular death is a research priority for hemodialysis patients, caregivers, and clinicians.

Dietary and other lifestyle choices, such as smoking and physical activity, are potentially modifiable determinants of health with substantial public health benefit. Dietary patterns, such as the Mediterranean and Dietary Approaches to Stop Hypertension (DASH) diets, are associated with a $10 \%$ to $30 \%$ reduction in cardiovascular events and mortality. ${ }^{8-10}$ However, these dietary patterns have not been shown to be associated with improved survival in hemodialysis patients. ${ }^{11}$

Dietary guidelines suggest modifying the intake of individual nutrients in dialysis patients to control serum phosphate and potassium levels and fluid overload while maintaining a high protein and energy intake. ${ }^{12-14}$ However, there is limited high-certainty evidence showing that targeting single nutrients improves clinical outcomes. ${ }^{15-17}$ Assessments of dietary patterns overcome the limitations of an individual nutrient or food approach by accounting for correlations and interactions between nutrients and foods. 
In addition, whole dietary patterns are readily understandable to patients and policy makers and therefore are suitable candidate interventions.

In a previous analysis of the DIET-HD study, we examined the association between existing dietary patterns (Mediterranean and DASH diets) and survival among hemodialysis patients in a multinational setting. ${ }^{11}$ In the present analysis, principal component analysis has been conducted in the same cohort to generate data-driven patterns reflecting the eating behavior of the DIET-HD hemodialysis population. This approach can support greater understanding of the prognosis associated with real-world dietary practices in hemodialysis patients. ${ }^{18,19}$ The aim of this analysis was to evaluate the association of commonly practiced dietary patterns with cardiovascular and all-cause mortality among adults treated with hemodialysis.

\section{Methods}

\section{Study Design}

This analysis is based on data from the Dietary Intake, Death and Hospitalization in Adults With End-Stage Kidney Disease Treated With Hemodialysis (DIET-HD) study, which has been described previously. ${ }^{20}$ In brief, it is a multinational prospective cohort study of food frequency intake among adults treated with long-term outpatient hemodialysis in 11 countries in Europe (France, Germany, Italy, Hungary, Poland, Portugal, Romania, Spain, Sweden, and Turkey) and South America (Argentina). This analysis is reported according to the Strengthening the Reporting of Observational Studies in Epidemiology (STROBE) guidelines. ${ }^{21}$

\section{Study Population}

Adults with kidney failure treated with long-term hemodialysis (at least 90 days) were eligible for inclusion in
DIET-HD. Patients were excluded if they were unable to complete the food frequency questionnaire (FFQ), had life expectancy less than 6 months, or anticipated kidney transplantation within 6 months of recruitment according to their treating clinician. All participants gave written informed consent. The study was conducted in accordance with the Declaration of Helsinki and was approved by the relevant institutional ethics committees.

\section{Dietary Intake Assessment}

Participants completed the Global Allergy and Asthma European Network (GA ${ }^{2}$ LEN) FFQ during a routine hemodialysis treatment, either independently or assisted by an interviewer (in case of severe clinical conditions or limited literacy). ${ }^{20}$ The FFQ was designed as a single, standardized, and internationally validated instrument to ascertain dietary intake facilitating international comparisons. ${ }^{22}$ It records the consumption of 210 foods during the previous 12 months as frequencies from never to 4 or more times per day. Responses to the FFQ were converted into average servings per week. ${ }^{23}$ Total energy intake was estimated from food intakes considering standard portion size and using the latest available McCance \& Widdowson's Food Composition Tables. ${ }^{24,25}$ Patients with $>20 \%$ missing answers or implausible responses (total energy intake not within 3 standard deviations [SDs] from the logtransformed mean) in the FFQ were excluded from the DIET-HD analyses (Fig 1).

\section{Covariates}

Baseline demographic and clinical characteristics were obtained within 1 month of enrollment using data linkage with a centralized routinely collected administrative database. $^{20}$ Data were provided by participants' treating clinicians using medical records for laboratory, clinical, and dialysis characteristics and participants' self-reported surveys for lifestyle characteristics.

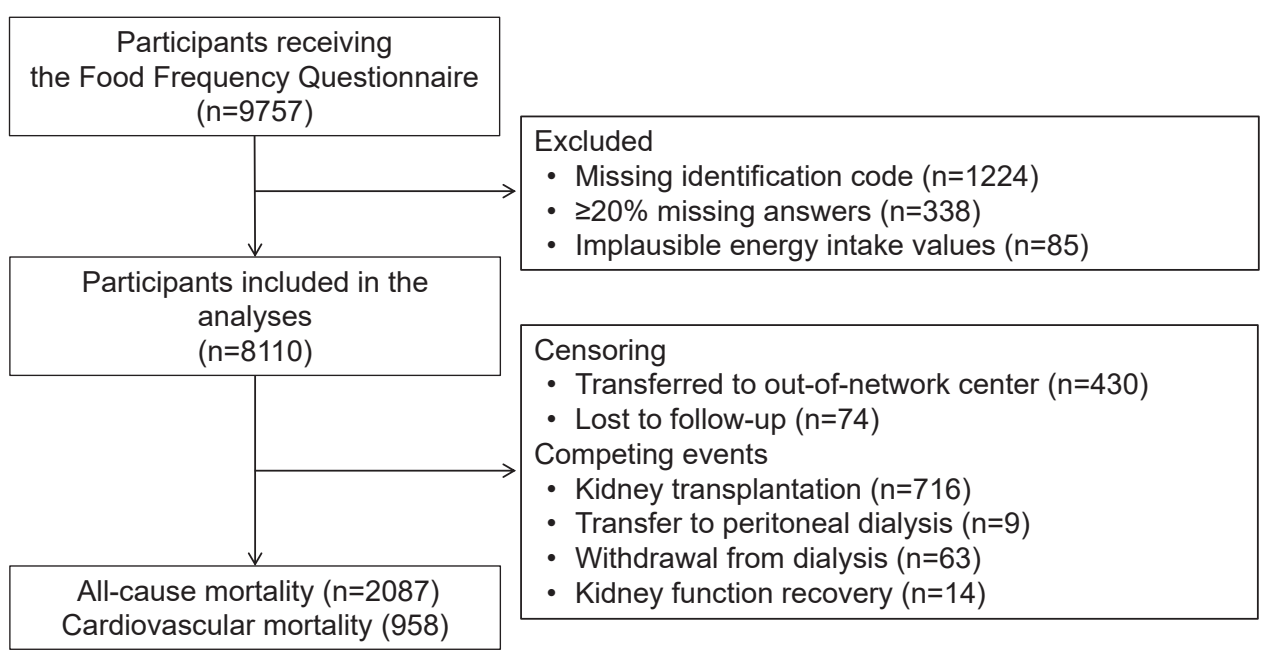

Figure 1. Study flow chart. 


\section{Outcomes}

Cardiovascular and all-cause mortality (while on maintenance hemodialysis) were identified through data linkage to a centralized administrative database. Causes of death were obtained from death certificates and recorded according to the US coding for the end-stage kidney disease population. $^{26,27}$ Cardiovascular mortality was defined as sudden death or death due to acute myocardial infarction, pericarditis, atherosclerotic heart disease, cardiomyopathy, cardiac arrhythmia, cardiac arrest, valvular heart disease, pulmonary edema, congestive cardiac failure, and cerebrovascular accident, including intracranial hemorrhage, ischemic brain damage/anoxic encephalopathy, or hemorrhage from ruptured vascular aneurysm. All-cause mortality was death from any cause.

\section{Statistical Methods}

Analyses were conducted using SAS, version 9.4 (SAS Institute), and STATA, version 14 (StataCorp).

\section{Dietary Pattern Analysis}

The common dietary patterns were characterized using principal component analysis. This was performed using data concerning food items reported to be consumed at least once per week by $>5 \%$ of participants. ${ }^{23}$ To account for the variability of food intake across countries and identify dietary patterns that were generalizable to all participating countries, we used a meta-analytical approach to calculate pooled Pearson correlation coefficients of foods listed in the FFQ. ${ }^{23,28,29}$ First, food variables were standardized (by SD scaling) by country. Second, within each country, Pearson correlation coefficients were evaluated for each pair of food items. Third, country-specific correlation coefficients were converted into Fisher z scores to improve normality. Fourth, Fisher $\mathrm{z}$ scores were given a weight proportional to the sample size of the country of interest (for each pair of food items, the associated Fisher z score was multiplied by the number of observations for that pair of foods within the country of interest and divided by the total number of observations for the same pair of foods in the entire cohort). An inverse Fisher transformation was applied to obtain a pooled matrix of Pearson correlation coefficients ${ }^{29}$ (Item S1). Finally, principal component analysis with varimax rotation was applied to the pooled matrix of Pearson correlation coefficients identifying dietary patterns that were applicable to the data drawn from all countries. The number of patterns to be retained was chosen based on examination of the scree plot (Fig S1) and interpretability. Food items with absolute factor loadings (equivalent to Pearson correlation coefficients with the pattern) $\geq 0.30$ were considered as main constituents of a dietary pattern.

Participants received a score for each identified dietary pattern reflecting how closely their diet resembled that pattern, with higher scores indicating closer resemblance. Dietary pattern scores were standardized variables (mean equal to zero and SD equal to 1) calculated by summing standardized intake of the food items weighted by their factor loadings on the relevant pattern. When computing dietary pattern scores, missing intakes of individual food items (ranging from 0.3\%-3.3\%) were imputed using single imputation by chained equations with predictive mean matching. ${ }^{30,31}$ Dietary pattern scores and their quartiles were considered as the primary exposure for survival analysis.

\section{Survival Analysis}

Fractional polynomials were used to test for a linear association between dietary pattern scores and mortality (no deviation from linearity was found). Survival time for each participant was defined as days from FFQ administration to the date of death (cardiovascular or all-cause), kidney transplantation, withdrawal from dialysis, recovery of kidney function, transfer outside the network, transfer to peritoneal dialysis, loss to follow-up, or end of the followup period. For both cardiovascular and all-cause mortality (while on hemodialysis), competing events were kidney transplantation, withdrawal from dialysis, recovery of kidney function, and transfer to peritoneal dialysis, whereas transfer outside the network, loss to follow-up, and end of the follow-up period were censoring events. For cardiovascular mortality, noncardiovascular mortality was also a competing event. For analyses of cardiovascular mortality, patients who had died from noncardiovascular causes were treated as censoring using cause-specific hazards models.

Univariable mortality associations between mortality and quartiles of dietary pattern scores were examined in cumulative probability plots. In the presence of competing events, cumulative probabilities were estimated using cumulative incidence functions and compared using Gray test. Univariable and multivariable cause-specific hazards models were fitted with a frailty, a random effect to account for countries as clusters. Dietary pattern scores were modeled both as continuous variables and as quartiles. Results were presented per each 1-SD greater and as hazard ratio (HR) with the associated 95\% confidence interval (CI), respectively. The lowest quartile was used as the reference category. Backwards elimination was used to select covariates for inclusion in the multivariable models retaining those (aside from energy intake, sex, physical activity, education, and diabetes, which were clinically relevant variables specified a priori) associated with mortality $(\mathrm{P}<0.05)$ or with a clinically meaningful impact on the HR for the outcome of the dietary pattern scores $(\geq 10 \%)$.

Analyses of cardiovascular mortality were adjusted for age, sex, daily physical activity, education (secondary vs none/primary), diabetes, smoking (current or former vs never), myocardial infarction, stroke, vascular access type (fistula vs graft/catheter), body mass index (categories according to World Health Organization), albumin (tertiles), Charlson comorbidity index score (quartiles), 
serum phosphorus level, serum calcium level, hemoglobin level, urea clearance $(\mathrm{Kt} / \mathrm{V})$, and total energy intake (per $1,000-\mathrm{kcal} / \mathrm{d}$ increase). Analyses of all-cause mortality were adjusted for the same variables with the exception of stroke and the additions of being wait-listed for a transplant and time on dialysis.

All analyses of the fruit and vegetable dietary pattern's score were adjusted for the Western dietary pattern's score and vice versa. We imputed missing covariates (while outcomes data were complete for all patients), using multiple imputation by chained equations (20 rounds). Interactions terms between dietary pattern scores (modeled as continuous) and age, sex, and body mass index were tested in the multivariable model (none was eligible for retention). The proportional hazards assumption was assessed by fitting time-dependent covariates in the multivariable model, for which a violation of proportionality was considered if $\mathrm{P}$ values of the time-dependent covariates were $<0.01$ (no violation was found).

\section{Sensitivity Analysis}

In sensitivity analysis of principal component analysis, oblique (promax) rotation was applied for the interpretation of dietary patterns. In survival analysis, a completecase analysis was conducted including only patients with complete data for covariates.

\section{Results}

\section{Participant Characteristics}

Overall, 9,757 hemodialysis patients completed the FFQ between January 2014 and January 2015. Of these, 8,110 (83\%) had complete and plausible dietary data and were followed up through June 27, 2017 (Fig 1). Baseline characteristics of the cohort are shown in Table 1.

\section{Dietary Patterns}

From the 210 available in the FFQ, 179 food items were included in the principal component analysis; 31 foods were excluded based on infrequent consumption. From the principal component analysis, the first 2 principal components, explaining $10 \%$ of the total variance in the dietary intake, were chosen (based on interpretability of the dietary patterns composition and the scree plot in Fig S1 showing an "elbow," indicating that after 2 components, each single additional component would explain little more of the variance) for dietary patterns. The same patterns were obtained when applying either varimax or promax rotation. Figure 2 and Table 2 report correlation coefficients (factor loadings from the principal component analysis) between individual food items and the identified dietary patterns showing which foods were the main constituents of each pattern. Intake of foods with low factor loadings $(<0.30)$ was similar between the 2 dietary patterns and therefore considered nondiscriminatory of the 2 identified patterns
Table 1. Baseline Characteristics of Participants

\begin{tabular}{|c|c|c|}
\hline Variable & $\begin{array}{l}\text { No. of } \\
\text { Participants } \\
\text { With Data }\end{array}$ & Overall \\
\hline \multicolumn{3}{|c|}{ Sociodemographic Characteristics } \\
\hline Age, y & 8,110 & $63 \pm 15$ \\
\hline Male sex & 8,110 & $4,691(58 \%)$ \\
\hline Life partner & 6,095 & $4,127(68 \%)$ \\
\hline Secondary education & 6,090 & $2,699(44 \%)$ \\
\hline Daily physical activity & 6,199 & $934(15 \%)$ \\
\hline Wait-listed for transplant & 8,094 & $1,496(18 \%)$ \\
\hline \multicolumn{3}{|l|}{ Clinical Characteristics } \\
\hline Current or former smoker & 6,280 & $2,068(33 \%)$ \\
\hline Body mass index & 7,872 & \\
\hline Underweight $\left(<18.5 \mathrm{~kg} / \mathrm{m}^{2}\right)$ & & $365(5 \%)$ \\
\hline $\begin{array}{l}\text { Normal range } \\
\left(18.5-24.9 \mathrm{~kg} / \mathrm{m}^{2}\right)\end{array}$ & & $3,309(42 \%)$ \\
\hline Preobese $\left(25.0-29.9 \mathrm{~kg} / \mathrm{m}^{2}\right)$ & & $2,659(34 \%)$ \\
\hline Obese $\left(\geq 30.0 \mathrm{~kg} / \mathrm{m}^{2}\right)$ & & $1,539(20 \%)$ \\
\hline Hypertension & 7,320 & $6,219(85 \%)$ \\
\hline Diabetes & 7,283 & $2,332(32 \%)$ \\
\hline Myocardial infarction & 7,239 & $838(12 \%)$ \\
\hline Stroke & 7,233 & $634(9 \%)$ \\
\hline Charlson comorbidity score & 8,110 & $6[4,8]$ \\
\hline
\end{tabular}

Laboratory Variables

\begin{tabular}{lll}
\hline Albumin, g/dL & 6,167 & $4.0 \pm 0.4$ \\
\hline Phosphorus, $\mathrm{mg} / \mathrm{dL}$ & 7,869 & $4.7 \pm 1.4$ \\
\hline Calcium, $\mathrm{mg} / \mathrm{dL}$ & 7,870 & $8.9 \pm 0.7$ \\
\hline Hemoglobin, g/dL & 7,869 & $11.1 \pm 1.3$ \\
\hline Potassium, mEq/L & 2,357 & $5.0 \pm 0.7$ \\
\hline Dialysis Characteristics & & \\
\hline Arteriovenous fistula & 8,051 & $64,81(80 \%)$ \\
\hline Time on dialysis, y & 8,108 & $4[2,7]$ \\
\hline Kt/V urea & 7,818 & $1.7 \pm 0.3$ \\
\hline Food Group, servings/wk & &
\end{tabular}

Food Group, servings/wk

\begin{tabular}{lll}
\hline Stone fruit & 8,105 & $2.0[0.5,6.0]$ \\
\hline Citrus fruit & 8,103 & $2.5[1.0,7.0]$ \\
\hline Pome fruit & 8,096 & $6.0[1.5,8.0]$ \\
\hline Leafy green vegetables & 8,097 & $1.5[0.5,3.5]$ \\
\hline Cruciferous vegetables & 8,105 & $1.0[0.5,2.0]$ \\
\hline Red and orange vegetables & 8,109 & $6.0[3.0,9.5]$ \\
\hline Potatoes & 8,104 & $2.0[1.0,3.5]$ \\
\hline Eggs & 8,100 & $0.5[0.0,1.0]$ \\
\hline Red and processed meat & 8,110 & $1.5[0.5,4.0]$ \\
\hline Pork & 8,085 & $0.5[0.0,1.0]$ \\
\hline $\begin{array}{l}\text { Fish (cured, smoked, } \\
\text { tinned) }\end{array}$ & 8,104 & $0.5[0.0,1.0]$ \\
\hline
\end{tabular}

Note: Data are expressed as mean \pm standard deviation, median [interquartile range], or number (percentage). Body mass index categories are defined according to the World Health Organization. Food groups are based on selected food components of the identified patterns (Fig 2). Stone fruit: peach, plum, cherries, nectarine, and apricot; citrus fruit: orange, mandarin/tangerine, grapefruit, and lemon; pome fruit: apple and pear; leafy green vegetables: spinach and lettuce cruciferous vegetables: cabbage, cauliflower, and broccoli; red and orange vegetables: sweet peppers, tomato, carrots, and pumpkin; potatoes: French fries, potato in salads, potato tortilla (omelette), potato dumpling, gnocchi, and mashed potatoes; eggs: egg-based desserts and egg-based savory dishes; red and processed meat: bacon, dried cured sausages, minced beef meat, beef burger, sausages, and meat pies; pork: cutlet, chop, steak, fillet, loin, pork ribs, and minced; fish (cured, smoked, and tinned): cured smoked fatty fish, cured smoked white fish, and tinned fish. 


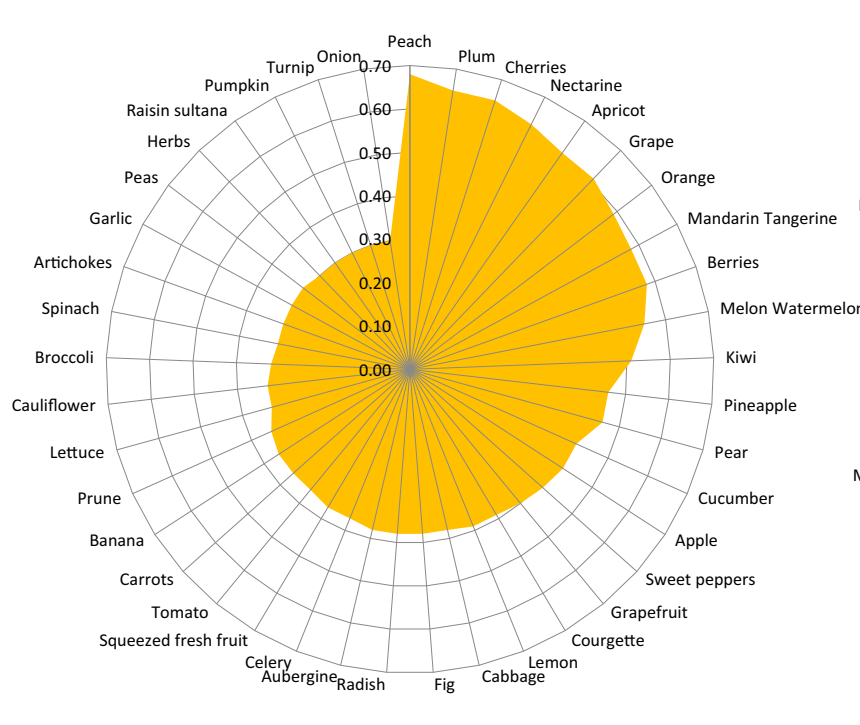

Fruit and vegetables dietary pattern

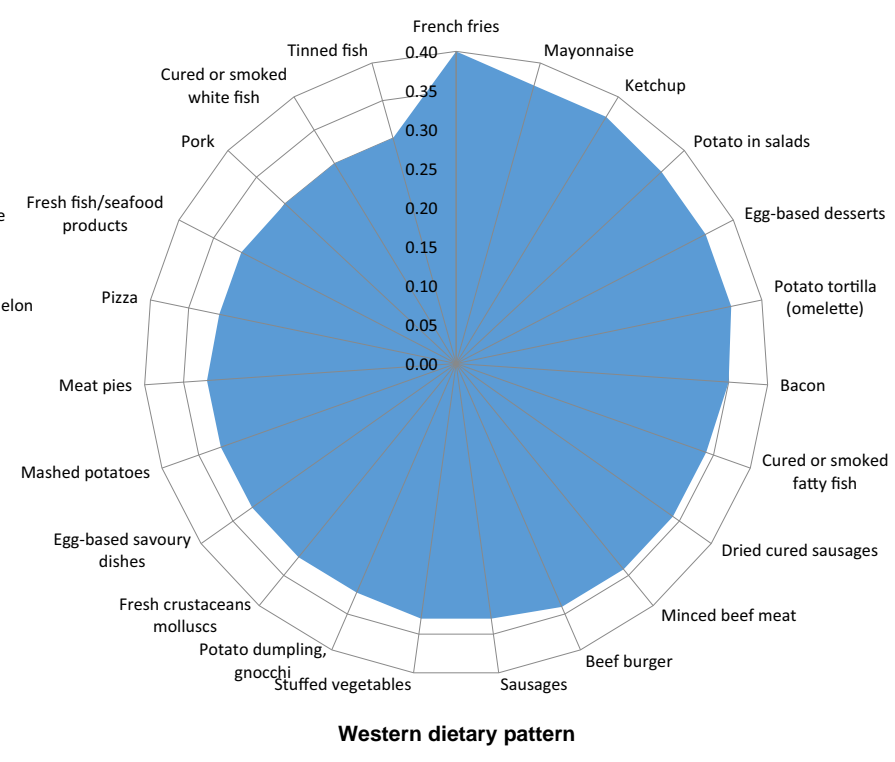

Figure 2. Food composition of the identified dietary patterns. Food items with a Pearson correlation coefficient $>0.30$ were considered main constituents of the dietary pattern and were included in the graphs.

The first dietary pattern was characterized by higher intake of fruit (including stone, citrus, and pome [pears and apples] fruit) and vegetables (including cruciferous and green leafy vegetables). The second pattern was characterized by higher intake of Western style foods, such as French fries, other potato meals, eggs, desserts, red and processed meat (including bacon, sausages, beef burger, and meat pie), fish (mostly cured, smoked, or tinned), and pizza. Consumption of the main food groups representative of the identified dietary patterns by quartiles of score is shown in Table S1. Higher levels of both dietary pattern scores in quartiles were associated with higher total energy intake (Table 3). Overall, both identified dietary patterns were consistently observed across the 11 countries (Tables S2 and S3). Based on their food compositions, the common dietary patterns were labeled as "fruit and vegetables" and "Western."

\section{Dietary Patterns and Cardiovascular Mortality}

During a median follow-up of 2.7 years $(18,666$ personyears), there were 2,087 (26\%) deaths, of which 958 $(46 \%)$ were attributable to cardiovascular diseases. The cumulative incidence function plots showing survival associated with dietary scores are shown in Figs S2 and S3.

In multivariable analyses, compared with patients in the lowest quartile of the fruit and vegetable dietary pattern score, adjusted HRs for cardiovascular mortality in the other quartiles, in ascending order, were $0.94(95 \% \mathrm{CI}$, $0.76-1.15), 0.83$ (95\% CI, 0.66-1.06), and 0.91 (95\% CI, $0.69-1.21$; Fig 3). For the Western dietary pattern, the corresponding estimates were 1.10 (95\% CI, 0.90-1.35), 1.11 (95\% CI, 0.87-1.41), and 1.09 (95\% CI, 0.80-1.49; Fig 4). Similar findings were observed in case-complete analyses. Results of continuous dietary patterns scores agreed with those of quartiles (Figs 3 and 4).

\section{Dietary Patterns and All-Cause Mortality}

Compared with patients in the lowest quartile of the fruit and vegetable dietary pattern score, adjusted HRs for all-cause mortality among those in the other quartiles, in ascending order, were 0.95 (95\% CI, 0.83-1.09), 0.84 (95\% CI, 0.71-0.99), and 0.87 (95\% CI, 0.72-1.05; Fig 3). For the Western dietary pattern, the corresponding estimates were 1.01 (95\% CI, 0.88-1.16), 1.00 (95\% CI, 0.85-1.18), and 1.14 (95\% CI, 0.93-1.41; Fig 4). Similar findings were observed in case-complete analyses. Results of continuous dietary patterns scores agreed with those of quartiles except for a signal of a significant association between higher fruit and vegetables dietary pattern score and lower all-cause mortality in case-complete analyses (Figs 3 and 4).

\section{Discussion}

In this study of 8,110 adults treated with hemodialysis, 2 common dietary patterns were observed: a fruit and vegetable diet, typically based on fruit and vegetables of low potassium content (such as pears and apples), and a Western diet favoring consumption of potatoes, eggs, and red and processed meat. These patterns were consistent across 10 European countries and Argentina. Over 3 years, with 2,087 deaths (958 cardiovascular related), there was no evidence of association between fruit and vegetable-based or a Western dietary pattern and cardiovascular and all-cause mortality.

The lack of association between the 2 identified dietary patterns and mortality may have several potential explanations. First, the influence of end-stage kidney disease (and 
Table 2. Pearson Correlation Coefficients Between Food Items and the Identified Dietary Patterns

\begin{tabular}{|c|c|c|}
\hline & $\begin{array}{l}\text { Fruit and } \\
\text { Vegetable } \\
\text { Dietary Pattern }\end{array}$ & $\begin{array}{l}\text { Western } \\
\text { Dietary } \\
\text { Pattern }\end{array}$ \\
\hline Peach & 0.68 & -0.08 \\
\hline Plum & 0.65 & -0.11 \\
\hline Cherries & 0.65 & -0.07 \\
\hline Nectarine & 0.63 & -0.06 \\
\hline Apricot & 0.61 & -0.06 \\
\hline Grape & 0.61 & -0.02 \\
\hline Orange & 0.59 & -0.02 \\
\hline Mandarin/tangerine & 0.58 & -0.05 \\
\hline Berries & 0.58 & -0.07 \\
\hline Melon or watermelon & 0.55 & -0.01 \\
\hline Kiwi & 0.51 & 0.03 \\
\hline Pineapple & 0.46 & 0.14 \\
\hline Pear & 0.46 & 0.00 \\
\hline Cucumber & 0.42 & 0.17 \\
\hline Apple & 0.42 & -0.02 \\
\hline Sweet peppers & 0.41 & 0.23 \\
\hline Grapefruit & 0.40 & 0.08 \\
\hline Courgette & 0.39 & 0.19 \\
\hline Lemon & 0.39 & 0.08 \\
\hline Cabbage & 0.38 & 0.25 \\
\hline Fig & 0.38 & 0.01 \\
\hline Radish & 0.38 & 0.17 \\
\hline Aubergine & 0.38 & 0.26 \\
\hline Celery & 0.37 & 0.20 \\
\hline Fresh squeezed fruit juice & 0.37 & 0.19 \\
\hline Tomato & 0.36 & 0.20 \\
\hline Carrots & 0.36 & 0.21 \\
\hline Banana & 0.36 & 0.11 \\
\hline Prune & 0.35 & 0.03 \\
\hline Lettuce & 0.33 & 0.18 \\
\hline Cauliflower & 0.33 & 0.25 \\
\hline Broccoli & 0.32 & 0.23 \\
\hline Spinach & 0.31 & 0.24 \\
\hline Artichokes & 0.31 & 0.16 \\
\hline Garlic & 0.31 & 0.16 \\
\hline Peas & 0.31 & 0.28 \\
\hline Herbs & 0.30 & 0.13 \\
\hline Raisin (sultana) & 0.30 & 0.12 \\
\hline Pumpkin & 0.30 & 0.23 \\
\hline Turnip or swede & 0.30 & 0.16 \\
\hline Onion & 0.30 & 0.16 \\
\hline French fries & 0.12 & 0.40 \\
\hline Mayonnaise & 0.04 & 0.37 \\
\hline Ketchup & 0.08 & 0.37 \\
\hline Potato in salads & 0.17 & 0.36 \\
\hline Egg-based desserts & 0.09 & 0.36 \\
\hline Potato tortilla (omelette) & 0.10 & 0.36 \\
\hline Bacon & 0.05 & 0.35 \\
\hline Cured or smoked fatty fish & 0.11 & 0.34 \\
\hline Dried cured sausages & 0.04 & 0.34 \\
\hline Minced beef meat & 0.11 & 0.34 \\
\hline Beef burger & 0.04 & 0.34 \\
\hline
\end{tabular}

Table 2 (Cont'd). Pearson Correlation Coefficients Between Food Items and the Identified Dietary Patterns

\begin{tabular}{llc}
\hline & $\begin{array}{l}\text { Fruit and } \\
\text { Vegetable } \\
\text { Dietary Pattern }\end{array}$ & $\begin{array}{l}\text { Western } \\
\text { Dietary } \\
\text { Pattern }\end{array}$ \\
\hline Sausages & 0.05 & 0.33 \\
\hline Stuffed vegetables & 0.17 & 0.33 \\
\hline Potato dumpling, gnocchi & 0.09 & 0.32 \\
\hline Fresh crustaceans or mollusks & 0.12 & 0.32 \\
\hline Egg-based savory dishes & 0.10 & 0.32 \\
\hline Mashed potatoes & 0.12 & 0.32 \\
\hline Meat pies & 0.08 & 0.32 \\
\hline Pizza & 0.06 & 0.31 \\
\hline $\begin{array}{l}\text { Other fresh fish/seafood } \\
\text { products (eg, taramasalata) }\end{array}$ & 0.08 & 0.31 \\
\hline $\begin{array}{l}\text { Pork (cutlet, chop, steak, fillet, } \\
\text { loin, pork ribs, minced) }\end{array}$ & 0.11 & 0.30 \\
\hline Cured or smoked white fish & 0.10 & 0.30 \\
\hline Tinned fish & 0.10 & 0.30 \\
\hline Note: Food itm with an absolute Pears
\end{tabular}

Note: Food items with an absolute Pearson correlation coefficient $\geq 0.30$ were considered main constituents of the dietary pattern and therefore were included in the table.

its comorbid conditions) on health could be so profound that factors such as diet, which had been shown to be beneficial for survival in the general population ${ }^{8-10,32,33}$ and patients with early- to moderate-stage chronic kidney disease, ${ }^{34}$ may have substantially smaller absolute effects on mortality in dialysis patients. This hypothesis is supported by results of another substudy of the DIET-HD study, which also showed little or no association between mortality and a priori dietary patterns considered healthy for the general population, namely the Mediterranean and DASH diets. ${ }^{11}$ Second, the relatively short follow-up may have precluded the detection of any significant association between mortality and these dietary patterns. Third, residual confounding from unmeasured factors (such as frailty or socioeconomic factors different from education [for which the analyses were adjusted]) may have masked any associations between the identified dietary patterns and mortality. Finally, the self-reported and single dietary assessment may have led to measurement error that may have biased results toward the null.

Although in univariable analysis and multivariable case-complete analysis, there was a significant association between higher fruit and vegetables dietary patterns score, treated as continuous variables, and lower all-cause mortality, this association was not confirmed in the primary analyses. These findings are to some extent in contrast with our previous hypothesis-driven analysis examining the role of fruit and vegetables as a specific food group in the same cohort, which consistently showed an association between higher intake of these foods and lower all-cause mortality. ${ }^{35}$ This inconsistency may be due to the different methodological approaches in defining the exposures of interest (data-driven patterns derived from intake of all the individual food items of the administered FFQ vs intake of fruit and vegetables measured from the 
Table 3. Daily Nutrients Intake by Quartiles of the Identified Dietary Pattern Scores

\begin{tabular}{|c|c|c|c|c|}
\hline & Score Quartile 1 & Score Quartile 2 & Score Quartile 3 & Score Quartile 4 \\
\hline \multicolumn{5}{|c|}{ Fruit and Vegetable Dietary Pattern } \\
\hline Total energy, kcal & $1,274(962-1,610)$ & $1,718(1,387-2,075)$ & $2,088(1,718-2,538)$ & $2,841(2,271-3,599)$ \\
\hline Protein, $\mathrm{g}$ & $62(45-83)$ & $85(65-110)$ & $104(81-133)$ & $138(105-182)$ \\
\hline Carbohydrates, $\mathrm{g}$ & $137(99-183)$ & $186(144-237)$ & $229(182-290)$ & $319(249-426)$ \\
\hline Fiber, $g$ & $7(5-10)$ & $10(8-13)$ & $14(11-17)$ & $20(15-27)$ \\
\hline Total fat, $\mathrm{g}$ & $50(35-66)$ & $67(51-85)$ & $82(64-104)$ & $111(84-144)$ \\
\hline Sugar, g & $56(38-82)$ & $84(61-116)$ & $112(83-150)$ & $171(126-240)$ \\
\hline Phosphorus, mg & $880(646-1,269)$ & $1,211(923-1,587)$ & $1,519(1,175-2,008)$ & $2,103(1,604-2,823)$ \\
\hline Sodium, mg & $857(608-1,198)$ & $1,157(867-1,513)$ & $1,421(1,057-1,900)$ & $2,019(1,480-2,811)$ \\
\hline Potassium, mg & $2,107(1,569-2,864)$ & $3,001(2,403-3,732)$ & $3,891(3,172-4,890)$ & $5,891(4,655-7,629)$ \\
\hline \multicolumn{5}{|c|}{ Western Dietary Pattern } \\
\hline Total energy, kcal & $1,205(925-1,502)$ & $1,673(1,397-1,979)$ & $2,117(1,813-2,459)$ & $2,972(2,460-3,681)$ \\
\hline Protein, g & $58(43-77)$ & $82(64-104)$ & 105 (84-127) & $149(118-190)$ \\
\hline Carbohydrates, g & $134(97-178)$ & $184(143-232)$ & $232(187-286)$ & $323(256-421)$ \\
\hline Fiber, g & $7(5-10)$ & $10(8-14)$ & $13(10-17)$ & $20(15-26)$ \\
\hline Total fat, $\mathrm{g}$ & $45(33-59)$ & $64(52-79)$ & $83(69-101)$ & $121(97-153)$ \\
\hline Sugar, g & $59(39-89)$ & $84(61-119)$ & $111(80-151)$ & $163(117-225)$ \\
\hline Phosphorus, mg & $838(624-1,182)$ & $1,161(922-1,525)$ & $1,493(1,214-1,884)$ & $2,225(1,719-2,907)$ \\
\hline Sodium, mg & $789(569-1,058)$ & $1,101(858-1,412)$ & $1,448(1,168-1,820)$ & $2,222(1,695-2,959)$ \\
\hline Potassium, mg & $2,119(1,571-2,929)$ & $2,992(2,395-3,803)$ & $3,835(3,149-4,817)$ & $5,796(4,585-7,523)$ \\
\hline
\end{tabular}

responses to 2 general questions about the overall fruit and vegetable consumption). However, inconsistency in the prognosis of fruit and vegetable intake between 2 differing measurement approaches may also suggest that any relationship between fruit and vegetable intake and survival, if any, may be of low magnitude.

We are not aware of previous research that has examined dietary patterns using principal component analysis in the hemodialysis population. However, the 2 dietary patterns identified in our study, fruit and vegetable-based and Western, are consistent with those generally identified in studies of data-driven dietary patterns in the general population. ${ }^{18,36-38}$ These findings suggest that although hemodialysis patients are advised to modify components of their diet, their overall dietary intake may not differ substantively from that of the general population. Identification of a Western dietary pattern is also in agreement with previous research reporting high consumption of fast and processed food among patients on hemodialysis. ${ }^{39,40}$ This may reflect the challenges (including financial) of adhering to dietary modifications, time or energy limitations preventing shopping and preparation of food, or may be consistent with the widespread consumption of convenience foods observed in the contemporary society. ${ }^{41,42}$

This study has several strengths. The analysis investigated dietary patterns in patients receiving hemodialysis by embracing a whole dietary intake approach compared with the existing research in this setting, which is centered on individual nutrients (such as protein, phosphate, and potassium). The study assessed empirical dietary patterns, recognizing that dietary intake among hemodialysis patients may be systematically different than the wider community due to altered appetite, lower socioeconomic status, and dietary modification advice. As such, this analysis integrates our previous analysis of a priori dietary patterns for a comprehensive evaluation of the relationship between overall diet quality and survival, using different methodological approaches. The study applied a meta-analytic principal component analysis to a large variety of foods deriving dietary patterns common to many countries.

There are also potential limitations due to the observational nature of the study, challenges inherent in the assessment of a complex exposure such as diet (in general and in the specific setting of hemodialysis), and the applied method of ascertaining dietary patterns. The study relied on an FFQ, which used standard food portion sizes and has been validated against plasma phospholipid fatty acids, but not with other dietary assessment methods and not in the setting of hemodialysis. Participants completed the FFQ during the hemodialysis procedure, when they may have experienced adverse events, such as intradialytic hypotension, which may hamper the accuracy of the reporting. Due to the self-reported nature of the FFQ, social desirability bias was also possible. Collectively, these limitations may have led to measurement error and misclassification of the exposures. The direction and magnitude of potential measurement error are difficult to predict with certainty and may have led to under- or overestimation of the observed association between dietary patterns and clinical outcomes. ${ }^{43,44}$ 


\section{Cardiovascular mortality}

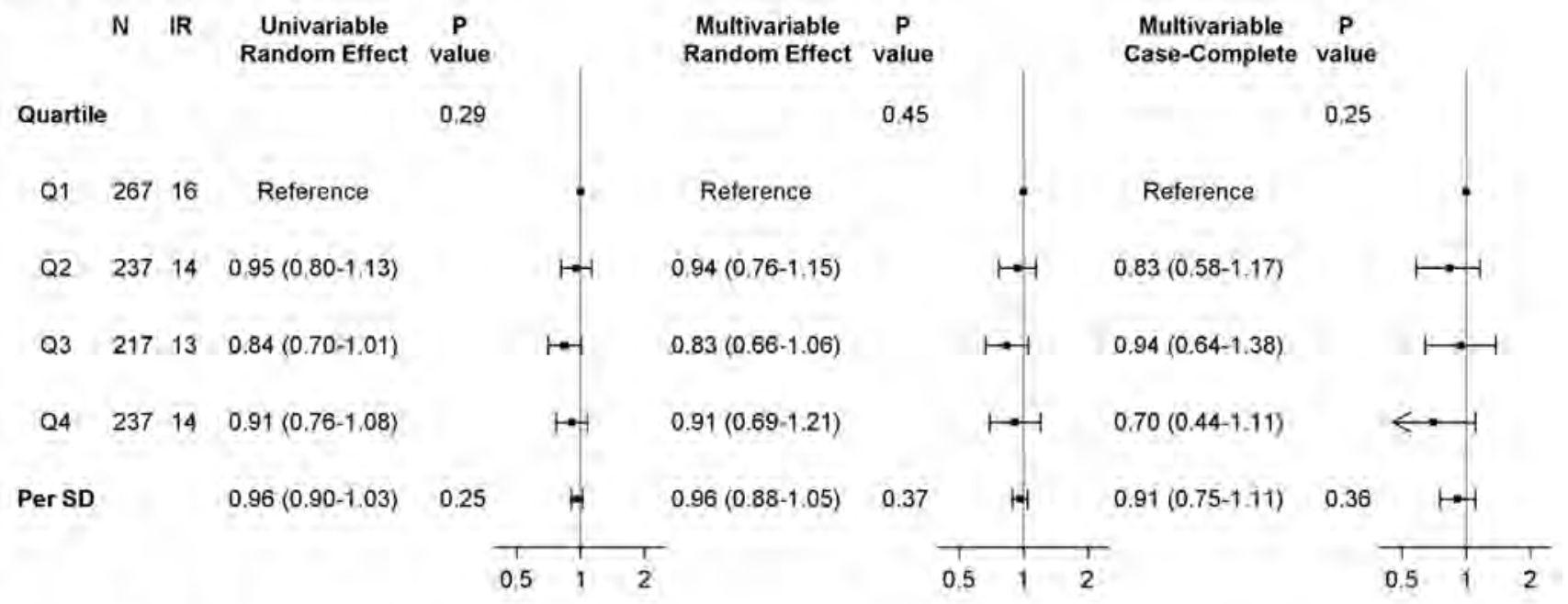

All-cause mortality

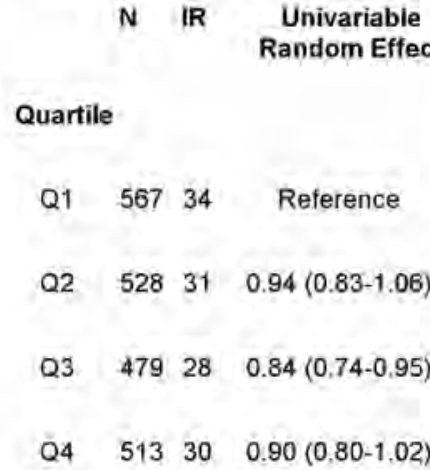

Per SD

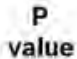

0.04

.

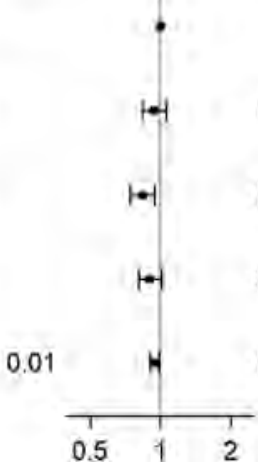

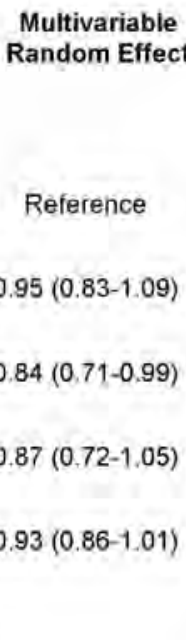

P

value

0.17

(1)

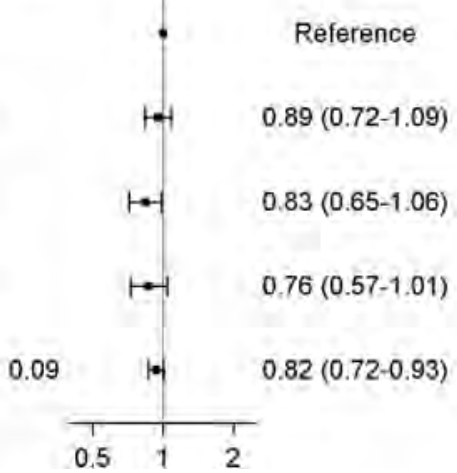

Multivariable $\mathbf{P}$ Case-Complete value

0.31

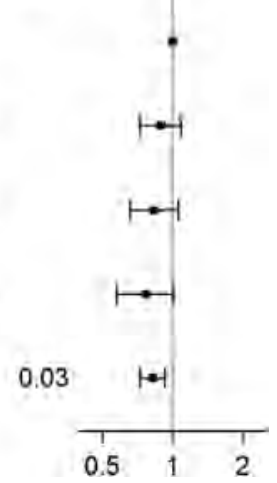

Figure 3. Mortality incidences and hazard ratios (95\% confidence interval) by quartiles of the fruit and vegetable dietary pattern score. Multivariable analyses for cardiovascular mortality were adjusted for country (fixed effect in competing-risk analysis and random effect in all others), sex, daily physical activity, education (secondary vs none/primary), diabetes, smoking (current or former vs never), myocardial infarction, stroke, vascular access type (fistula vs graft/catheter), body mass index (categories according to World Health Organization), albumin (tertiles), Charlson comorbidity score (quartiles [Q]), age, phosphorus level, calcium level, hemoglobin level, $\mathrm{Kt} / \mathrm{V}$, and energy intake $(1,000 \mathrm{kcal} / \mathrm{d}$ increase). Multivariable analyses for all-cause mortality were adjusted for the same variables with the exception of stroke, and the addition of time on dialysis and being wait-listed for transplantation. Analyses of each pattern were adjusted for the other one. Abbreviations: IR, incidence rate; N, number of events; per SD, per standard deviation increase.

In addition, the single dietary assessment did not allow detection of any potential change in dietary habits and patterns over time, particularly in relation to the health decline that can occur in an individual on hemodialysis. Selection bias was also possible due to exclusion of $17 \%$ of patients with incomplete or implausible dietary data. Principal component analysis was able to explain $10 \%$ of the variance in dietary exposure, indicating that there likely were other aspects of dietary intake that were not captured by the best-fit patterns of fruit and vegetables and Western dietary scores. However, a small amount of explained variance is not uncommon in studies of principal component analysis. ${ }^{23,28,36,41,45}$ The data-driven approach could limit the generalizability of our findings, which may not be applicable to patients living outside Europe and Argentina.

These findings of little or no association of dietary patterns with mortality outcomes added to the uncertain benefits of restricting single dietary components ${ }^{12,15-17}$ leads to the conclusion that further investigation of dietary recommendations in hemodialysis is warranted. This is especially relevant given the substantial adverse 


\section{Cardiovascular mortality}

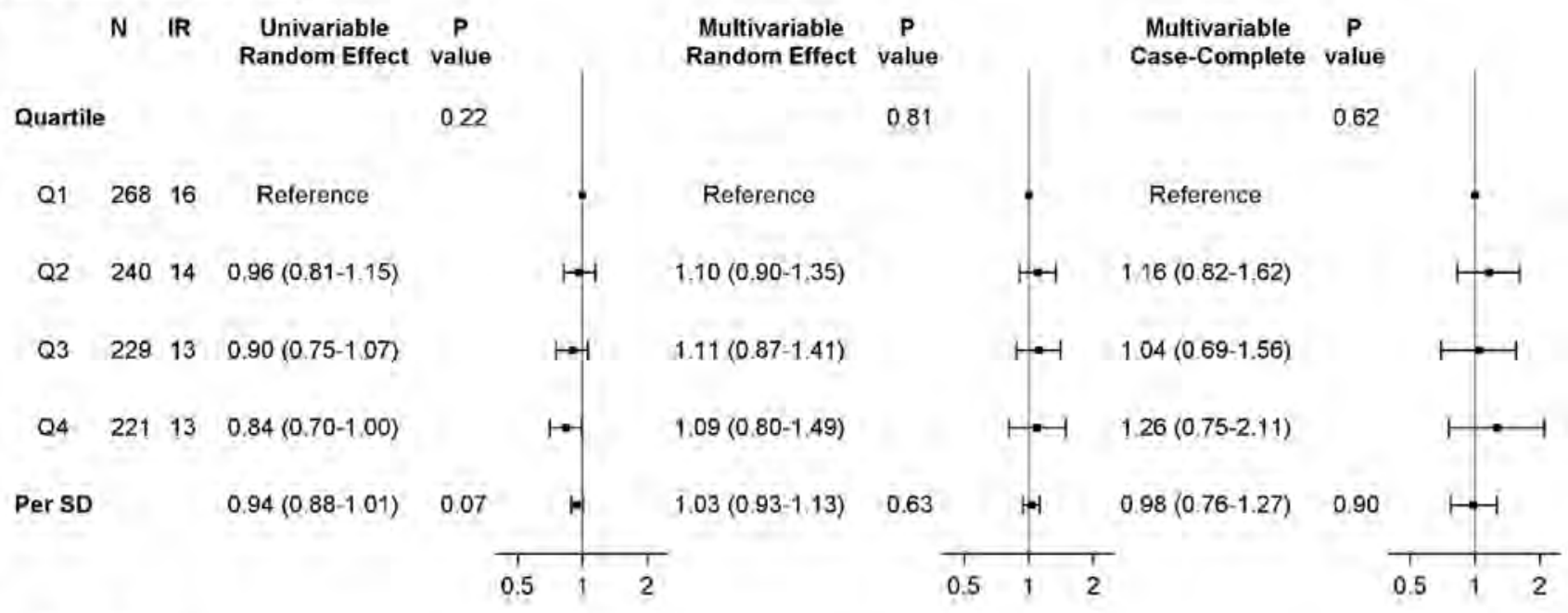

All-cause mortality
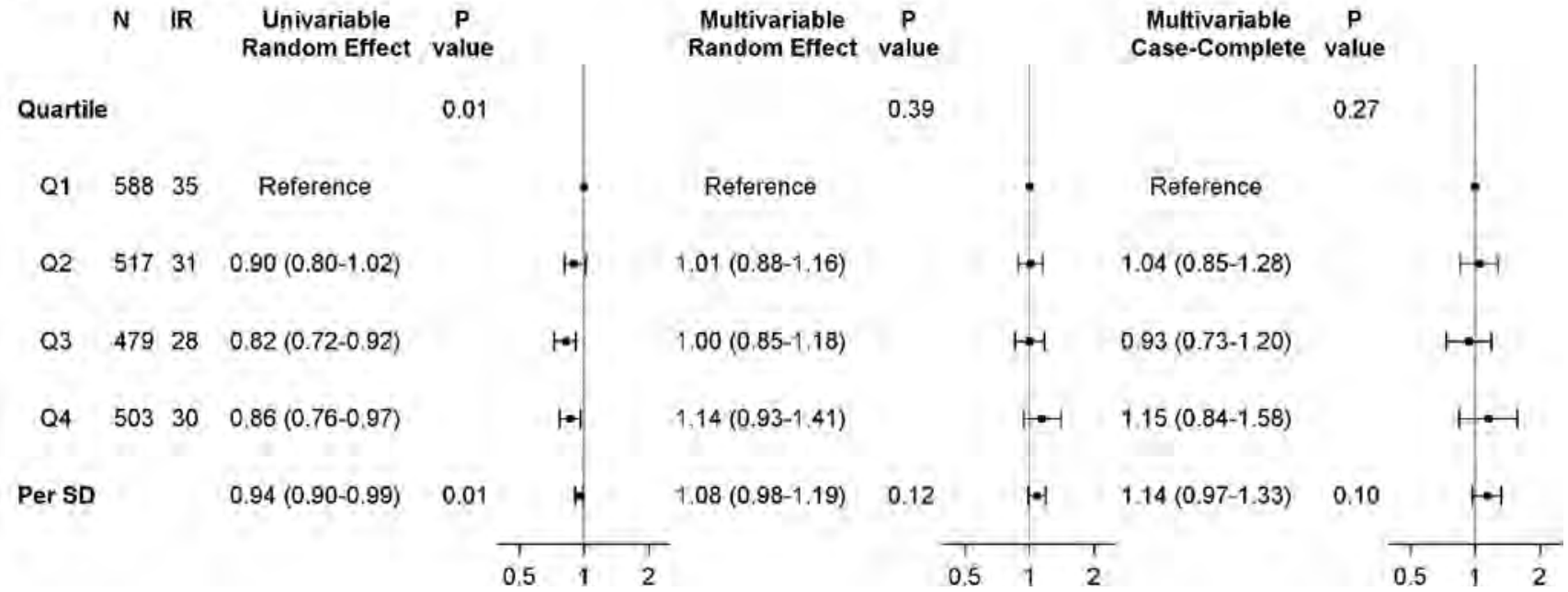

Figure 4. Mortality incidences and hazard ratios (95\% confidence interval) by quartiles (Q) of the Western dietary pattern score. Multivariable analyses for cardiovascular mortality were adjusted for country (fixed effect in competing-risk analysis and random effect in all others), sex, daily physical activity, education (secondary vs none/primary), diabetes, smoking (current or former vs never), myocardial infarction, stroke, vascular access type (fistula vs graft/catheter), body mass index (categories according to World Health Organization), albumin (tertiles), Charlson comorbidity score (quartiles), age, phosphorus level, calcium level, hemoglobin level, Kt/V, and energy intake $(1,000 \mathrm{kcal} / \mathrm{d}$ increase). Multivariable analyses for all-cause mortality were adjusted for the same variables with the exception of stroke and the addition of time on dialysis and being wait-listed for transplantation. Analyses of each pattern were adjusted for the other one. Abbreviations: IR, incidence rate; $\mathrm{N}$, number of events; per SD, per standard deviation increase.

impact that dietary restrictions have on quality of life. ${ }^{46,47}$ This call for further evaluation is supported by other studies. ${ }^{42,48}$ For instance, recent observational studies of either dietary phosphorus restrictions or phosphate binders found better indexes of nutritional status and greater survival associated with less stringent dietary control. ${ }^{49,50}$ Based on these collective data, future trials should investigate whether a more liberal approach to the intake of fruit and vegetables or dietary control can offer similar survival and improved quality of life for patients treated with long-term hemodialysis.

In conclusion, our findings did not confirm an association between mortality among patients receiving long- term hemodialysis and the extent to which dietary patterns were either high in fruit and vegetables or consistent with a Western diet. Trials investigating the benefits and harms of more inclusive diets are warranted.

\section{Supplementary Material}

\section{Supplementary File (PDF)}

Figure S1: Results from the principal component analysis with the varimax rotation

Figure S2: Cumulative incidence function plots for cardiovascular and all-cause mortality by quartiles of the fruit and vegetable dietary pattern score. 
Figure S3: Cumulative incidence function plots for cardiovascular and all-cause mortality by quartiles of the Western dietary pattern score.

Item S1: Meta-analytic procedure for pooled Pearson correlation coefficients

Table S1: Servings per week of the main food groups representative of the identified dietary patterns by patterns quartiles score.

Table S2: Pearson correlation coefficients of food items with the fruit and vegetable dietary pattern by country.

Table S3: Pearson correlation coefficients of food items with the Western dietary pattern by country.

\section{Article Information}

DIET-HD Investigators and Dieticians: Argentina: A. Badino, L. Petracci, C. Villareal, M. Soto, M. Arias, F. Vera, V. Quispe, S. Morales, D. Bueno, R. Bargna, G. Peñaloza, L. Alcalde, J. Dayer, A. Milán, N. Centurión, A. Ramos, E. De Orta, S. Menardi, N. Austa Bel, E. Marileo, N. Junqueras, C. Favalli, R. Trioni, G. Valle, M. López, C. Marinaro, A. Fernandez, J. Corral, E. Nattiello, S. Marone, J. García, G. Carrizo, P. González, O. Delicia, M. Maza, M. Chauque, J. Mora, D. Grbavac, L. López, M. Alonso, C. Villalba, M. Simon, M. Cernadas, C. Moscatelli, I. Vilamajó, C. Tursky, M. Martínez, F. Villalba, D. Pereira, S. Araujo, H. López, V. Alonso, B. Vázquez, M. Rapetti, S. Raña, M. Capdevila, C. Ljubich, M. Acosta, M. Coombes, V. Doria, M. Ávila, D. Cáceres, E. Geandet, C. Romero, E. Morales, C. Recalde, S. Marone, M. Casanú, B. Lococo, O. Da Cruz, C. Focsaner, D. Galarce, L. Albarracín, E. Vescovo, M. Gravielle, D. Florio, L. Baumgart, M. Corbalán, V. Aguilera, O. Hermida, C. Galli, L. Ziombra, A. Gutierrez, S. Frydelund, A. Hardaman, A. Maciel, M. Arrigo, C. Mato Mira, J. Leibovich, R. Paparone, E. Muller, A. Malimar, I. Leocadio, W. Cruz, S. Tirado, A. Peñalba, R. Cejas, S. Mansilla, C. Campos, E. Abrego, P. Chávez, G. Corpacci, A. Echavarría, C. Engler, P. Vergara, M. Hubeli, G. Redondo, B. Noroña; France: C. Boriceanu, M. Lankester, J.L. Poignet, Y. Saingra, M. Indreies, J. Santini, A. Mahi, A. Robert, P. Bouvier, T. Merzouk, F. Villemain, A. Pajot, F. Tollis, M. Brahim-Bounab, A. Benmoussa, S. Albitar, M.C. Guimont, P. Ciobotaru, A. Guerin, M. Diaconita; Germany: S.H. Hoischen, J. Saupe, I. Ullmann, S. Grosser, J. Kunow, S. Grueger, D. Bischoff, J. Benders, P. Worch, T. Pfab, N. Kamin, M. Roesch, M. May; Hungary: K. Albert, I. Csaszar, E. Kiss, D. Kosa, A. Orosz, J. Redl, L. Kovacs, E. Varga, M. Szabo, K. Magyar, E. Zajko, A. Bereczki, J. Csikos, E. Kerekes, A. Mike, K. Steiner, E. Nemeth, K. Tolnai, A. Toth, J. Vinczene, S.z. Szummer, E. Tanyi, M. Szilvia; Italy: A.M. Murgo, N. Sanfilippo, N. Dambrosio, C. Saturno, G. Matera, M. Benevento, V. Greco, G. di Leo, S. Papagni, F. Alicino, A. Marangelli, F. Pedone, A.V. Cagnazzo, R. Antinoro, M.L. Sambati, C. Donatelli, F. Ranieri, F. Torsello, P. Steri, C. Riccardi, A. Flammini, L. Moscardelli, E. Boccia, M. Mantuano, R. Di Toro Mammarella, M. Meconizzi, R. Fichera, A. D'Angelo, G. Latassa, A. Molino, M. Fici, A. Lupo, G. Montalto, S. Messina, C. Capostagno, G. Randazzo, S. Pagano, G. Marino, D. Rallo, A. Maniscalco, O.M. Trovato, C. Strano, A. Failla, A. Bua, S. Campo, P. Nasisi, A. Salerno, S. Laudani, F. Grippaldi, D. Bertino, D.V. Di Benedetto, A. Puglisi, S. Chiarenza, M. Lentini Deuscit, C.M. Incardona, G. Scuto, C. Todaro, A. Dino, D. Novello, A. Coco; Poland: E. BocheńskaNowacka, A. Jaroszyński, J. Drabik, M. Wypych-Birecka, D. Daniewska, M. Drobisz, K. Doskocz, G. Wyrwicz-Zielińska, A. Kosicki, W. Ślizień, P. Rutkowski, S. Arentowicz, S. Dzimira, M. Grabowska, J. Ostrowski, A. Całka, T. Grzegorczyk, W. Dżugan, M. Mazur, M. Myślicki, M. Piechowska, D. Kozicka; Portugal: V. de Sá Martins, L. Aguiar, A.R. Mira, B. Velez, T. Pinheiro; Romania: E. Agapi, C.L. Ardelean, A. Baidog, G. Bako, M. Barb, A. Blaga, E. Bodurian, V. Bumbea, E. Dragan, D. Dumitrache, L. Florescu, N. Havasi, S. Hint, R. llies, A.G.M. Mandita, R.I. Marian, S.L. Medrihan,
L. Mitea, S. Mitea, R. Mocanu, D.C. Moro, M. Nitu, M.L. Popa, M. Popa, E. Railean, A.R. Scuturdean, K. Szentendrey, C.L. Teodoru, A. Varga; Spain: M. García, M. Olaya, V. Abujder, J. Carreras, A. López, F. Ros, G. Cuesta, A. García, E. Orero, E. Ros, S. Bea, J.L. Pizarro, S. Luengo, A. Romero, M. Navarro, L. Cermeño, A. Rodriguez, D. Lopez, A. Barrera, F. Montoya, J. Tajahuerce, M. Carro, M.Q. Cunill, S. Narci, T. Ballester, M.J. Soler, S. Traver, P.P. Buta, L. Cucuiat, L. Rosu, I. Garcia, C.M. Gavra, R. Gonzalez, S. Filimon, M. Peñalver, V. Benages, M.I. Cardo, E. García, P. Soler, E. Fernnandez, F. Popescu, R. Munteanu, E. Tanase, F. Sagau, D. Prades, S. Esteller, E. Gonzalez, R. Martinez, A. Diago, J. Torres, E. Perez, C. Garcia, I. Lluch, J. Forcano, M. Fóns, A. Rodríguez, N.A. Millán, J. Fernández, B. Ferreiro, M. Otero, V. Pesqueira, S. Abal, R. Álvarez, C. Jorge, I. Rico, J. de Dios Ramiro, L. Duzy, A. Soto, J.L. Lopez, Y. Diaz, I. Herrero, M. Farré, C. Blasco, S. Ferrás, M.J. Agost, C. Miracle, J. Farto; Sweden: J. Goch, K.S. Katzarski, A. Wulcan; Turkey: H. Akbiber, H. Arslan, L. Bicen, A. Buyukkiraz, R. Celik, I.S. Dogan, S. Erkalkan, A. Ertas, U. Hark, E. Iravul, M. Karakaya, K. Mengu, S. Ongun, Z. Ozkan, A. Ozlu, N. Ozveren, H.M. Sifil, N. Sonmez Turksoz, Z. Yilmaz.

Authors' Full Names and Academic Degrees: Valeria M. Saglimbene, MScMed, Germaine Wong, MBBS, PhD, Armando Teixeira-Pinto, PhD, Marinella Ruospo, PhD, Vanessa GarciaLarsen, PhD, Suetonia C. Palmer, MB ChB, PhD, Patrizia Natale, MScMed, Katrina Campbell, PhD, Juan-Jesus Carrero, PhD, Peter Stenvinkel, MD, PhD, Letizia Gargano, MSc, Angelo M. Murgo, MD, David W. Johnson, MBBS, PhD, Marcello Tonelli, MD, Rubén Gelfman, MD, Eduardo Celia, MD, Tevfik Ecder, MD, Amparo G. Bernat, MD, Domingo Del Castillo, MD, Delia Timofte, MD, Marietta Török, MD, Anna Bednarek-Skublewska, MD, Jan Duława, MD, Paul Stroumza, MD, Martin Hansis, MD, Elisabeth Fabricius, MD, Paolo Felaco, MD, Charlotta Wollheim, MSc, Jörgen Hegbrant, MD, PhD, Jonathan C. Craig, $\mathrm{MB} \mathrm{ChB}, \mathrm{PhD}$, and Giovanni F.M. Strippoli, MD, PhD.

Authors' Affiliations: Faculty of Medicine and Health, Sydney School of Public Health, University of Sydney, Sydney, Australia (VMS, GW, A-TP, GFMS); Diaverum Medical-Scientific Office, Diaverum, Lund, Sweden (VMS, MR, PN, LG, AMM, RG, EC, TE, AGB, DDC, DT, MTörök, AB-S, JD, PStroumza, MH, EF, CW, JH, GFMS); Centre for Kidney Research, Children's Hospital at Westmead (GW, A-TP); Department of Renal Medicine, Westmead Hospital, Westmead, Australia (GW); Department of International Health, Johns Hopkins Bloomberg School of Public Health, Baltimore, MD (VGL); Department of Medicine, University of Otago Christchurch, Christchurch, New Zealand (SCP); Department of Emergency and Organ Transplantation, University of Bari, Bari, Italy (PN, GFMS); Department of Nutrition and Dietetics, University of Queensland at Princess Alexandra Hospital, Woolloongabba, Queensland, Australia (KC); Department of Medical Epidemiology and Biostatistics (J-JC) and Division of Renal Medicine, Department of Clinical Science, Intervention and Technology(PStenvinkel), Karolinska Institutet, Stockholm, Sweden; Division of Medicine, Department of Nephrology, University of Queensland at the Princess Alexandra Hospital (DWJ); Translational Research Institute, University of Queensland, Woolloongabba, Australia (DWJ); Cumming School of Medicine, Health Sciences Centre, University of Calgary, Calgary, Alberta, Canada (MTonelli); Medical University of Lublin, Lublin (AB-S); Medical University of Silesia, Katowice, Poland (JD); Nephrology and dialysis Presidio Ospedaliero Penne, Unita' Sanitaria Locale Pescara (PF); College of Medicine and Public Health, Flinders University, Adelaide, Australia (JCC); and Diaverum Academy, Diaverum, Bari, Italy (GFMS).

Address for Correspondence: Valeria M. Saglimbene, MScMed, Sydney School of Public Health, University of Sydney, Edward Ford Building A27, NSW 2006, Australia. E-mail: vsag1982@ gmail.com 
Authors' Contributions: Conception and design: VMS, GW, SCP, KC, VGL, JJC, JCC, GFMS; data acquisition: MR, PN, LG, AMM, RG, EC, TE, DDC, AGB, DT, MTörök, ABS, JD, PStroumza, MH, $E F, \quad P F, J H, C W ;$ data analysis: VMS, GW, ATP; data interpretation: VMS, GW, ATP, JCC, VGL, SCP, KC, JJC, PStenvinkel, DJ, MTonelli, GFMS; study supervision and mentorship: GW, JCC, SCP, GFMS. Each author contributed important intellectual content during manuscript drafting or revision, approved the final version of the submitted manuscript, and accepts accountability for the overall work by ensuring that questions pertaining to the accuracy or integrity of any portion of the work are appropriately investigated and resolved.

Support: The DIET-HD study received unrestricted funding from Diaverum, a provider of renal services; all DIET-HD Investigators and Dieticians are based at Diaverum facilities. Funding was applied to cover overhead costs for study coordinators in each contributing country and material printing. The funding organization had no role in study design; collection, analysis and interpretation of the data; writing the manuscript; or the decision to submit the manuscript for publication.

Financial Disclosure: The authors declare that they have no relevant financial interests.

Acknowledgements: We thank the provider of renal services Diaverum for covering overhead costs for study coordinators in each contributing country and material printing; $\mathrm{Dr}$ Liliya Chamitava for insights into the methodological aspects of principal component analysis in nutritional epidemiology; and $G A^{2} L E N$ for facilitating the use of the $G A^{2} L E N ~ F F Q$.

Peer Review: Received December 19, 2018. Evaluated by 2 external peer reviewers, with direct editorial input from a Statistics/ Methods Editor, an Associate Editor, and the Editor-in-Chief. Accepted in revised form May 26, 2019.

\section{References}

1. Saran R, Robinson B, Abbott KC, et al. US Renal Data System 2017 Annual Data Report: epidemiology of kidney disease in the United States. Am J Kidney Dis. 2018;71(3)(suppl 1):S1S676.

2. Thompson S, James M, Wiebe N, et al. Cause of death in patients with reduced kidney function. J Am Soc Nephrol. 2015;26(10):2504-2511.

3. Palmer SC, Mavridis D, Navarese E, et al. Comparative efficacy and safety of blood pressure-lowering agents in adults with diabetes and kidney disease: a network meta-analysis. Lancet. 2015;385(9982):2047-2056.

4. Lo C, Toyama T, Wang Y, et al. Insulin and glucose-lowering agents for treating people with diabetes and chronic kidney disease. Cochrane Database Syst Rev. 2018;9: CD011798.

5. Palmer SC, Di Micco L, Razavian M, et al. Effects of antiplatelet therapy on mortality and cardiovascular and bleeding outcomes in persons with chronic kidney disease: a systematic review and meta-analysis. Ann Intern Med. 2012;156(6):445459.

6. Palmer SC, Craig JC, Navaneethan SD, Tonelli M, Pellegrini F, Strippoli GF. Benefits and harms of statin therapy for persons with chronic kidney disease: a systematic review and meta-analysis. Ann Intern Med. 2012;157(4): 263-275.

7. Tong A, Manns B, Wang AYM, et al. Implementing core outcomes in kidney disease: report of the Standardized Outcomes in Nephrology (SONG) implementation workshop. Kidney Int. 2018; https://doi.org/10.1016/j.kint.2018.08.018.
8. Stewart RAH. Primary prevention of cardiovascular disease with a Mediterranean diet supplemented with extra-virgin olive oil or nuts. N Engl J Med. 2018;379(14):1387-1388.

9. Chen ST, Maruthur NM, Appel LJ. The effect of dietary patterns on estimated coronary heart disease risk: results from the $\mathrm{Di}$ etary Approaches to Stop Hypertension (DASH) trial. Circ Cardiovasc Qual Outcomes. 2010;3(5):484-489.

10. Salehi-Abargouei A, Maghsoudi Z, Shirani F, Azadbakht L. Effects of Dietary Approaches to Stop Hypertension (DASH)style diet on fatal or nonfatal cardiovascular diseases incidence: a systematic review and meta-analysis on observational prospective studies. Nutrition. 2013;29(4):611-618.

11. Saglimbene VM, Wong G, Craig JC, et al. The association of Mediterranean and DASH diets with mortality in adults on hemodialysis: the DIET-HD Multinational Cohort Study. J Am Soc Nephrol. 2018;29(6):1741-1751.

12. Ash S, Campbell KL, Bogard J, Millichamp A. Nutrition prescription to achieve positive outcomes in chronic kidney disease: a systematic review. Nutrients. 2014;6(1):416-451.

13. Fouque $D$, Vennegoor $M$, ter Wee $P$, et al. EBPG guideline on nutrition. Nephrol Dial Transplant. 2007;22(suppl 2):ii45ii87.

14. Kalantar-Zadeh K, Fouque D. Nutritional management of chronic kidney disease. N Engl J Med. 2017;377:1765-1776.

15. Liu Z, Su G, Guo X, et al. Dietary interventions for mineral and bone disorder in people with chronic kidney disease. Cochrane Database Syst Rev. 2015;9:CD010350.

16. McMahon EJ, Campbell KL, Bauer JD, Mudge DW. Altered dietary salt intake for people with chronic kidney disease. Cochrane Database Syst Rev. 2015;(2):CD010070.

17. Naylor $\mathrm{HL}$, Jackson $\mathrm{H}$, Walker $\mathrm{GH}$, et al. British Dietetic Association evidence-based guidelines for the protein requirements of adults undergoing maintenance haemodialysis or peritoneal dialysis. J Hum Nutr Diet. 2013;26(4):315-328.

18. Garcia-Larsen V, Morton V, Norat $T$, et al. Dietary patterns derived from principal component analysis (PCA) and risk of colorectal cancer: a systematic review and meta-analysis. Eur J Clin Nutr. 2018; https://doi.org/10.1038/s41430-018-0234-7.

19. Newby PK, Tucker KL. Empirically derived eating patterns using factor or cluster analysis: a review. Nutr Rev. 2004;62(5):177203.

20. Palmer SC, Ruospo M, Campbell KL, et al. Nutrition and dietary intake and their association with mortality and hospitalisation in adults with chronic kidney disease treated with haemodialysis: protocol for DIET-HD, a prospective multinational cohort study. BMJ Open. 2015;5(3):e006897.

21. von Elm E, Altman DG, Egger M, Pocock SJ, Gotzsche PC Vandenbroucke JP. Strengthening the Reporting of Observational Studies in Epidemiology (STROBE) statement: guidelines for reporting observational studies. BMJ. 2007;335 (7624):806-808.

22. Garcia-Larsen V, Luczynska M, Kowalski ML, et al. Use of a common food frequency questionnaire (FFQ) to assess dietary patterns and their relation to allergy and asthma in Europe: pilot study of the GA2LEN FFO. Eur J Clin Nutr. 2011;65(6):750756.

23. Bakolis I, Hooper R, Bachert C, et al. Dietary patterns and respiratory health in adults from nine European countriesevidence from the GA(2) LEN study. Clin Exp Allergy. 2018;48(11):1474-1482.

24. Food Standards Agency; Mills A, Patel S, Crawley E, eds. Food Portion Sizes (Maff Handbook). 3rd revised ed. UK: Stationery Office Books (TSO); 2005.

25. Roe M, Pinchen H, Church S, Finglas P. McCance and Widdowson's the composition of foods seventh summary edition 
and updated composition of foods integrated dataset. Nutr Bull. 2015;40:36-39.

26. Cause-Specific Mortality Rates. https://www.usrds.org/2017/ view/v2_00_appx.aspx. Accessed December 1, 2018.

27. ESRD Death Notification Form. https://www.cms.gov/ Medicare/CMS-Forms/CMS-Forms/downloads/cms2746.pdf. Accessed December 1, 2018.

28. Hooper R, Heinrich J, Omenaas E, et al. Dietary patterns and risk of asthma: results from three countries in European Community Respiratory Health Survey-II. Br J Nutr. 2010;103(9): 1354-1365.

29. Rosenthal R. Meta-analytic Preocedures for Social Research. London, UK: Sage; 1991:87.

30. Morris TP, White IR, Royston P. Tuning multiple imputation by predictive mean matching and local residual draws. BMC Med Res Methodol. 2014;14:75.

31. Schenker NT, Taylor JMG. Partially parametric techniques for multiple imputation. Comput Stat Data Anal. 1996;22:425-446.

32. de Lorgeril M, Renaud S, Mamelle N, et al. Mediterranean alpha-linolenic acid-rich diet in secondary prevention of coronary heart disease. Lancet. 1994;343(8911):1454-1459.

33. Sofi F, Macchi C, Abbate R, Gensini GF, Casini A. Mediterranean diet and health status: an updated meta-analysis and a proposal for a literature-based adherence score. Public Health Nutr. 2014;17(12):2769-2782.

34. Kelly JT, Palmer SC, Wai SN, et al. Healthy dietary patterns and risk of mortality and ESRD in CKD: a meta-analysis of cohort studies. Clin J Am Soc Nephrol. 2017;12(2):272-279.

35. Saglimbene V, Wong G, Ruospo M, et al. Fruit and vegetable intake and mortality in adults undergoing maintenance hemodialysis. Clin J Am Soc Nephrol. 2019;14(2):250-260.

36. Martinez-Gonzalez MA, Zazpe I, Razquin C, et al. Empiricallyderived food patterns and the risk of total mortality and cardiovascular events in the PREDIMED study. Clin Nutr. 2015;34(5):859-867.

37. Fung TT, Willett WC, Stampfer MJ, Manson JE, Hu FB. Dietary patterns and the risk of coronary heart disease in women. Arch Intern Med. 2001;161(15):1857-1862.

38. Schulze MB, Hoffmann K. Methodological approaches to study dietary patterns in relation to risk of coronary heart disease and stroke. Br J Nutr. 2006;95(5):860-869.
39. Butt S, Leon JB, David CL, Chang H, Sidhu S, Sehgal AR. The prevalence and nutritional implications of fast food consumption among patients receiving hemodialysis. J Ren Nutr. 2007;17(4):264-268.

40. Sarathy S, Sullivan C, Leon JB, Sehgal AR. Fast food, phosphorus-containing additives, and the renal diet. J Ren Nutr. 2008;18(5):466-470.

41. Gutierrez OM, Muntner P, Rizk DV, et al. Dietary patterns and risk of death and progression to ESRD in individuals with CKD: a cohort study. Am J Kidney Dis. 2014;64(2):204-213.

42. Kalantar-Zadeh K, Tortorici AR, Chen JL, et al. Dietary restrictions in dialysis patients: is there anything left to eat? Semin Dial. 2015;28(2):159-168.

43. Flegal KM, Keyl PM, Nieto FJ. Differential misclassification arising from nondifferential errors in exposure measurement. Am J Epidemiol. 1991;134(10):1233-1244.

44. Jurek AM, Greenland S, Maldonado G, Church TR. Proper interpretation of non-differential misclassification effects: expectations vs observations. Int J Epidemiol. 2005;34(3):680687.

45. Bamia C, Trichopoulos D, Ferrari P, et al. Dietary patterns and survival of older Europeans: the EPIC-Elderly Study (European Prospective Investigation into Cancer and Nutrition). Public Health Nutr. 2007;10(6):590-598.

46. Palmer SC, Hanson CS, Craig JC, et al. Dietary and fluid restrictions in CKD: a thematic synthesis of patient views from qualitative studies. Am J Kidney Dis. 2015;65(4):559573.

47. Stevenson J, Tong A, Gutman T, et al. Experiences and perspectives of dietary management among patients on hemodialysis: an interview study. J Ren Nutr. 2018;28(6):411-421.

48. Biruete A, Jeong JH, Barnes JL, Wilund KR. Modified nutritional recommendations to improve dietary patterns and outcomes in hemodialysis patients. J Ren Nutr. 2017;27(1):62-70.

49. Komaba H, Kakuta T, Wada T, Hida M, Suga T, Fukagawa M. Nutritional status and survival of maintenance hemodialysis patients receiving lanthanum carbonate. Nephrol Dial Transplant. 2018; https://doi.org/10.1093/ndt/gfy090.

50. Lynch KE, Lynch R, Curhan GC, Brunelli SM. Prescribed dietary phosphate restriction and survival among hemodialysis patients. Clin J Am Soc Nephrol. 2011;6(3):620-629. 